\title{
DE BIBLIOTHEEK VAN DE OUDE ST.-ANDRIESABDIJ
}

Al konden reeds 'n tweetal bijdragen, die evenwel het onderwerp geenszins uitputten, worden gewijd aan de bibliotheek van het oude St-Andries ${ }^{\mathbf{1}}$, toch is deze boekenverzameling blijkbaar nooit belangrijk geweest. Buiten enkele handschriften door de monniken van Affligem in I 188 achtergelaten ${ }^{2}$, buiten de liturgische handschriften in 1308 door abt de Colonia aangeschaft ${ }^{3}$, buiten de twee psalters die abt Roland van Steelandt door de Gentse Hiëronymieten liet vervaardigen ${ }^{4}$ en enkele antiphonaria door abt-bisschop Boudewijn Vilain (1509-1519) geschonken ${ }^{5}$, heeft de bibliotheek van St-Andries blijkbaar nooit talrijke noch kostbare codices in bezit gehad, waardoor zoveel andere benediktijnerabdijen voor altijd vermaard zijn geworden.

(1) D. DebruYne, Un catalogue des manuscrits de l'ancienne abbaye de Saint-André-lez-Bruges, Revue bénédictine, 37 (1925), blz. 273-275; N. N. Huyghebaert, Note sur les bibliothèques d'Affigem et de ses prieurés au XIIe siècle, in Miscellanea Gessleriana, Antwerpen 1948, blz. 6 Iо -6 I6.

$\left.{ }^{2}{ }^{2}\right)$ N. N. Huyghebaert, Note sur les bibliothèques d'Affligem, blz. 6 I2.

$\left(^{3}\right)$ "Plurimos conscribi fecit (abt H. De Colonia) libros missales, passionales, alios que divine auctoritatis atque doctrine, qui usque hodie penes nos habentur, pro quibus numerosam valde eum necesse fuit exposuisse pecuniam. Nam plerique preter forme quantitatem tante artis industria et ornatus magnificentia confecti sunt, ut nostre etatis etiam expertissimis scriptoribus admirationi sint. "A. Goethals, Chronica monasterii Sancti Andreae juxta Brugas (ed. W. H. James WEALE), Brugge, 1868, blz. 99.

$\left({ }^{4}\right)$ "Anno XXII ${ }^{\circ}\left[{ }^{5}\right.$ 22] apportata fuere a gandavo duo nova magna psalteria apud fratres scripta pro quibus exsolvit abbas Rolandus XII libros gr." A. GoEThals, Chronica monasterii Sancti Andreae, (BRUGGE, Stadsbibliotheek, hs. 569 , fol. $\left.125 \mathrm{v}^{\circ}\right)$; over de onuitgegeven laatste hoofdstukken van Goethals, zie N. HuYghebaERT, Histoire d'une chronique, in Les Cahiers de Saint-André, 6 (1949), blz. II7-122.

$\left({ }^{5}\right)$ "Item diversos libros cantatorios fecit scribi (Balduinus)." A. Goethass, Chronica monasterii Sancti Andreae, (hs. 569, fol. 122). 
Wat kan ze thans nog van haar schatten tonen? De Isidoruscodex van de Vatikaanse bibliotheek ${ }^{6}$, de kroniek van Arnout Goethals, die gelukkig nog te Brugge wordt bewaard ${ }^{7}$, en een rituale monasticum uit de bibliotheek van Millau in het verre Aveyron, door dezelfde Goethals gecalligrafieerd, gebonden en waarschijnlijk ook verlucht ${ }^{8}$.

Het is wellicht geen louter toeval, dat de twee enige handschriften die uit St-Andries stammen (want de Isidoruscodex is eigenlijk een product van het Affligemse scriptorium) van de hand zijn van Arnout Goethals. Hij is dan ook de typische vertegenwoordiger van de nieuwe humanistische strekking die men te St-Andries kan waarnemen na de invoering van de Bursfelder hervorming?.

In 1500 te Gent geboren, had Arnout Goethals zijn opleiding genoten bij de gunstig gekende Broeders van het Gemene Leven, ook Hiëronymieten genoemd. Het is zeer waarschijnlijk bij hen dat hij die vakkennis opdeed, waarvan het prachtige rituale van Millau een zo merkwaardig getuige is. In ${ }_{5}{ }_{1} 8$ te St-Andries binnengetreden, trof hij er als prior de Waal Jean Philippart, oud monnik van Gembloers, die dit ambt van ${ }_{51} 18$ tot ${ }_{1524}$ bekleedde. Ziehier wat Arnout Goethals enkele jaren later over hem wist te zeggen : „Alhoewel hij geleerd was en verdienstelijk onder meer dan één opzicht, was hij niettemin minder geschikt voor de taak van prior. Gedurende de tijd van zijn prioraat zorgde hij er evenwel

( $\left.{ }^{6}\right)$ Reg. 239; zie A. Wilmart, Codices Reginenses latini (= Bibliothecae apostolicae Vaticanae Codices manu scripti), I, Città del Vaticano, I937, blz. 566-567.

(7) Hs. 569 ; zie A. De Poorter, Catalogue des manuscrits de la Bibliothèque Publique de la Ville de Bruges, Gembloers-Parijs, I934, blz. 690 .

( $\left.{ }^{8}\right)$ "Hunc gemmatum scripsit, ligavit et contulit monasterio Sancti Andreae juxta Brugas D. Arnulphus Goethals ejusdem monasterii monachus professus et sacerdos, anno Domini et etatis sue $\mathrm{XXX}^{0}$ in anno 1530, : N. HuYghebaERT, Le chroniqueur Arnold Goethals, in Les Cahiers de Saint-André, 6 (1949), blz. 177-178; vgl. Revue bénédictine, 37 (1925), blz. 273.

( ${ }^{9}$ ) N. Huyghebaert, De Bursfelder reform in de Sint-Andriesabdij, in Horae Monasticae, I (Fulgens radiatur), Tielt, 1947, blz. 24I-259. 
voor dat onze bibliotheek met tal van schone boeken werd verrijkt ${ }^{10}$."

Besefte dom Philippart zijn ongeschiktheid, of verlangde hij naar een vreedzamer oord om in angulo cum libello de rest van zijn dagen door te brengen? Wat hier ook van zij, hij zegde vaarwel aan het benediktijnerleven om in 1524 naar de kartuizerorde over te gaan in Genadedal ${ }^{11}$. Enkele jaren later, tussen $\mathrm{I}_{534}$ en $\mathrm{I}_{54} 6 \mathrm{zou}$ ook onze kroniekschrijver A. Goethals naar de kartuizers overgaan ${ }^{12}$.

Hoe deze merkwaardige aantrekkingskracht verklaard, die de kartuizerorde op onze St-Andriese humanisten uitoefende ? Het feit kan weliswaar ten dele verklaard worden door de inwendige toestand, door de moeizame inenting van de Bursfelder hervorming, door het van staatswege aanstellen van onwaardige of al te jeudige prelaten, zoals Roland van Steelandt of Jehan Asset. Maar dit herhaaldelijk voorkomen van een overgaan naar de kartuizers wijst ons nog op iets anders, op iets dat in betrekking staat met de bibliotheek van St-Andries en enig licht kan werpen op de samenstelling van de boekerij onder prior Jean Philippart.

Toen de pauselijke nuntius Hiëronymus Aleander, door de paus belast met het afkondigen van de bulle Exsurge in het Duitse Rijk en in de Nederlanden, in I52I naar Brugge kwam waar hij de Keizer hoopte te ontmoeten (7-26 Augustus), gewerden hem ongunstige berichten nopens de benediktijnen en de kartuizers van deze stad. Bleek het niet dat deze ,lediggangers en neurasthenieken" besmet waren met de nieuwe geest en, op de koop toe, verstokte lezers van Erasmus?

De nuntius stond reeds op het punt met het keizerlijk hof te vertrekken; doch hij achtte het zijn plicht zijn vertrek uit te stellen en aanstonds in te grijpen. Hij nam het vooral op tegen de kartuizers van Genadedal. Zijn rapporten leren ons

(10) A. Goethals, Chronica Sancti Andreae, (hs. 569, fol. 124 vo).

(11) A. Goethals, ibidem.

(12) Arnout Goethals wordt nog als monnik van St.-Andries vermeldt in een alte van 26 November 1534 (BRUGGE, Rijksarchief, bl. 5364); in November I 546 was hij reeds kartuizer (BRuSSEL, ARA., Etat et Audience, 852). 
dat hij zinnens was ze in een kapitulaire zitting bijeen te roepen en hen streng de les te spellen. De bedreiging, hen al hun bezittingen te ontnemen, zou, zo meende althans de nuntius, een heilzame indruk maken. ${ }^{13}$

Of Aleander nog de tijd vond om eveneens de benediktijnen van St-Andries, die een uur buiten de stad woonden en ook minder talrijk waren, te verontrusten, is niet heel waarschijnlijk, al ware het heel zeker niet minder nodig geweest. Immers

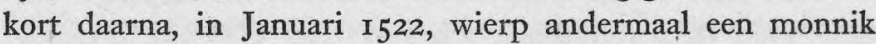
van St-Andries de kap over de haag ${ }^{\mathbf{1 4}}$. Gebeurde dit onder invloed van de opvattingen van Erasmus, of uit afkeer voor de Bursfelder hervorming? De vraag is moeilijk te beantwoorden.

Uit de tijd van dom Jean Philippart dagtekenen wellicht de drie van St-Andries afkomstige wiegedrukken die in de Brugse stadsboekerij worden bewaard ${ }^{15}$ : het Supplementum Chronicarum van Jacobus Bergomensis (Venetië I492), het Speculum naturale van Vincentius van Beauvais (Venetië 1494) en het Liber Chronicarum van Hartmann Schedel (Augsburg I497), alsook de postinkunabel Tractatus de profectu religioso van St. Bonaventura (Parijs, circa $\left.{ }^{1520}\right)^{16}$. Gewis, geen enkel van deze vier boekjes verdient de strenge veroordeling van de nuntius, zo min trouwens als de meeste inkunabels en

(13) P. FREDERICQ, Corpus documentorum inquisitionis haergeticae pravitatis Neerlandicae, V, Gent, I902, blz. 408; vgl. P. KalkofF, Die Anfänge der Gegenreformation in den Niederlanden, II, Halle, 1904, blz. 30-32; N. N. HuYGheBaERT, De Bursfelder Reform, blz. 250$25 \mathrm{I}$.

(14) A. Goethats, Chronica Sancti Andreae (ed. W. H. James WEALE, blz. 174.). Het zij hier bemerkt dat de eerste Lutheranen te Brugge slechts in $\mathbf{1 5 2 7}$ worden gesignaleerd. C. EVERAERT, De eerste protestanten te Brugge, in Biekorf 34 (1928) blz. 97-104.

(15) A. De Poorter, Listes des incunables de la bibliothèque publique de la ville de Bruges, in Annales Soc. Emul. Bruges, 64 (19r4), blz. 211, 229, 231 .

$\left({ }^{16}\right)$ Dit werk werd te koop gesteld op de boekenveiling Baron Jean de Brouwer (Brussel, ro/Ir Oktober 1947), nr 42 van de catalogus. Het kleine in-octavo droeg, volgens de catalogus, het exlibris ,van een monnik van St.-Andries". Het is ons niet bekend wie er thans de bezitter van is. 
postinkunables (tot $\mathbf{1 5 2}_{52}$ ) die wij in de latere catalogus aantreffen. Doch betreffende deze catalogus van omstreeks 1720 rijst een nieuwe vraag op : nog voor het einde van de XVIde eeuw, op 29 September 1578, werd de St-Andriesabdij bij verrassing door de Gentse Calvinisten overvallen en helemaal leeggeplunderd ${ }^{17}$. Welk was, in deze tragische uren, het lot van de oude bibliotheek van St-Andries? welke van de boeken, die met zoveel liefde en zorg door Jean Philippart en zijn opvolgers waren bijeengebracht, ontsnaptenaan de plundering ? Het is heel goed mogelijk dat de oudste boeken die wij in de catalogus van 1720 ontmoeten, voor het grootste deel pas in de XVIIde eeuw werden aangeschaft.

Wat hier ook van zij, de plundering van de abdij in 1578 , de verdrijving van de monniken tot aan de "reductie " van Brugge in ${ }_{15} 84$ of liever tot na de heroprichting van de abdij door de krachtdadige abt Jean Bourier, betekende het einde van de tweede fase in de geschiedenis van de bibliotheek van St-Andries. De derde zou geopend worden met het abbatiaat van dom Henricus van den Zype.

Abt Henricus van de Zype (I6I6-1659), een der ijverigsten om aan de oude abdij de glans ener ware vroomheid terug te schenken, was tevens een geleerd man. Aan de universiteiten van Dowaai en Leuven had hij het bachalaureaat in de godgeleerdheid behaald. Zeer jong nog werd hij tot prior aangesteld in de St-Jansabdij te Ieper, waar hij in 1594 zijn geloften had afgelegd. Een lijvig in-octavo over St. Gregorius de Grote, in I6II verschenen, vestigde de aandacht van de geleerde wereld op hem. In I6I6 tot abt van St-Andries benoemd, verloor hij niets van zijn studieijver : „,Hij was, bemerkt zijn biograaf, steeds verslonden in de lectuur van theologische boeken, handelend zowel over het dogma als over de moraal; voortdurend was hij an het werken aan verschillende verhandelingen ${ }^{18}$."

(17) Continuatio chronici monasterii S. Andreae juxta Brugas (DENDERMONDE, Bibliotheek van de S. Pieters-en-Paulusabdij, hs. 40); vgl. Gallia christiana, V, Parijs 1877 , kol. 274.

(18) Continuatio; vgl. J. F. Foppens, Bibliotheca belgica, I, Brussel I739, blz. 469 . 
Deze lofwaardige werkzaamheden vergden dan ook een rijk voorziene boekerij evenals een plaats om die boeken te bergen. En inderdaad zou abt van den Zype een bibliotheek laten bouwen. Dit gebeurde in nogal onverwachte omstandigheden.

Het was in 1626 . De abt wilde naast de slaapzaal der monniken een beerput laten delven. Deze vleugel, die, behalve het dormitorium tevens de kapittelzaal en de refter omvatte, dateerde uit 1252 en was dus reeds betrekkelijk oud. Toen men aan de voet van de muur begon te graven, dreigde heel het gebouw in te storten. Men moest de put onmiddellijk weer dicht gooien, en om de buitenmuur van de slaapzaal, die intussen fel was gaan overhellen, te stutten, was men verplicht er vlak naast een ander gebouw tegen op te trekken tot bijna op volle hoogte. De communiteit kreeg deze nieuwe vleugel als recreatiezaal („,choffoor”), en de verdieping zou dienst doen als bibliotheek. In de kroniek van St-Andries (we bedoelen hier de continuatio, de voortzetting van de kroniek van Arnout Goethals), waar deze episode uit het abbatiaat van dom van den Zype werd opgetekend, kunnen wij nog de volgende randnota lezen: „Etiam servit [haec domus] ad eumdem usum, I735".

Op een niet onaardig waterverfschilderijtje uit het jaar I7I 5 kan men nog de bibliotheek van dom van den Zype terugvinden : op de rand van een plattegrond van het goed ,Steenkin" te St-Andries, waarvan de gronden aan het beluik van de St-Andriesabdij paalden, schilderde landmeester F. Everaert een zicht op het koor van de abdijkerk en op de achtergevel van de slaapzaal. ${ }^{19}$ Het ,choffoor" der monniken, waarvan de schikking ondertussen misschien enigszins werd gewijzigd, komt eveneens terug op een plan van landmeester C. J. Bonnaert uit $\mathbf{r} 777^{20}$.

De samenstelling van de bibliotheek in deze jaren is ons

(19) BRUGGE, Rijksarchief, Kaarten en plannen, 598.

$\left({ }^{20}\right)$ Origineel niet meer voorhanden; een afschrift uit 1869 bevindt zich in de verzameling van Weled. Heer ridder Stanislas d'Ydewalle, te St.-Andries-bij-Brugge. 
bekend dank zij een XVIIIe eeuwse catalogus, heden nog bewaard in het stadsarchief te Brugge ${ }^{21}$.

Deze catalogus vormt een fraai register van $32 \times 22 \mathrm{~cm}$., 65 folios omvattend met I $_{3} 3$ beschreven en ${ }_{7} 7$ blank gebleven paginas. De perkamenten omslag draagt de volgende titel, die op folio $\mathrm{Ir}^{\mathrm{0}}$ wordt herhaald : „Catalogus librorum Abbatiae Sti Andree Apli Fuxta Brugas Ordinis Sti Pis Nri Benedicti."

De boeken worden in 16 secties gerangschikt en genummerd : S. Scripturae (22 nummers); Concilia (30 n.); Interpretes Sae Scripturae (127 n.); S. Patres (113 n.); Casuistae et Canonistae (22 n.); Controversistae (22 n.); Scholastici (260 n.); Philosophi (52 n.); Dictionnaria et Medici (22 n.); furistae et Canonistae (16I n.); Historici sacri (177 n.); Historici profani (219 n.); Conciones (186 n.); Libri Spirituales (469 n.); Miscellanei (240 n.); Grammaticales (125 n.).

De auteur van deze zorgvuldig aangelegde catalogus heeft telkens in een afzonderlijke kolom de locus imp(ressionis) aangetekend en het annus. Dit laat ons toe een eigenaardige en tevens leerzame statistiek op te stellen.

In onze catalogus zal men enkele wiegedrukken vinden, waarvan evenwel de datering (bijv. 1442) enkel met grote omzichtigheid kan gebruikt worden. Het jongste werk komt voor onder de Historici sacri, nl. de Acta S. Godelevae v. et m. authore \%. Bapt. Sollerio Soc. Fesu (Antwerpen 1720).

Worden de boeken volgens de datum van verschijnen gerangschikt, dan vinden wij voor de XVe eeuw : 23 boeken; voor de XVIe eeuw, $6_{32}$ boeken; voor de XVIIe eeuw 1395 boeken; voor het begin van de XVIIIe eeuw (I700-1720) slechts Io boeken! De XVIIe eeuw is dus het gouden tijdperk geweest voor onze bibliotheek. Dit valt goed te begrijpen. En willen we nu de boeken anders optellen, dan zullen we hiervan aanstonds de verklaring vinden.

1921 boeken zijn vóór I659 van de pers gekomen; slechts I39 boeken verschenen na deze datum. I4 Maart I659 overleed abt van den Zype. Het ligt dus voor de hand in hem de grote bevorderaar van de bibliotheek van St-Andries te zien, en

(21) Brugge, Stadsarchief, Fonds van Caloen, 42. 
meteen blijkt dat zijn opvolgers het belang van nuttige boeken niet meer zo duidelijk hebben ingezien. Tenzij natuurlijk men zou willen aannemen dat zij steeds de voorkeur aan oudere uitgaven zouden hebben gegeven.

In de kloosters is de zorg voor de boeken aan een bibliothecarius toevertrouwd. Slechts van één bibliothecaris van StAndries is de gedachtenis tot ons gekomen nl. dom Boudewijn Boens, van wiens werkzaamheid de sporen nog in verscheidene handschriften zijn terug te vinden.

Boudewijn Boens werd te Brugge geboren op 3 September I649 als zoon van Adriaan en Anna van Ghistele. Omstreeks 1670 legde hij de geloften af te St-Andries, terwijl zijn broeder Prosper Boens binnentrad bij de Augustijnen in de Eekhoutabdij, waar deze op II Januari I727 overleed ${ }^{22}$.

Boudewijn Boens is dispensator, d. w. z. hulpeconoom van zijn abdij geweest, ten minste tot in $\mathbf{1 6 8 6}$; dat jaar wordt hij door de abt, de twistzieke Placidus van Ockerhout, afgezet ${ }^{23}$. Later, waarschijnlijk na de dood van Pieter Carlier, die in 17 ro $7 \mathrm{I}$ jaar was en kort nadien moet overleden zijn, werd hij tot supprior benoemd. Dit ambt zou hij tot zijn dood waarnemen. Hij staat opgetekend op 25 Oktober in de obituaria van St Jan ten Berge en van de Eekhout ${ }^{24}$.

Dom Boens was geen ontontwikkeld man. Hij schreef vlot latijn, had enige kennis van kerkelijk recht en wist zich te gepaster ure de tekst van menig canon te herinneren, zoals bijv. tijdens zijn geschil met abt van Ockerhout ${ }^{25}$. In ${ }^{16} 69$ was hij reeds bibliothecaris en hij bleef het wellicht tot aan zijn dood $^{26}$.

${ }^{(22)}$ Obituaire de l'abbaye de l'Eeckhout (ed. W. H. James WEALE), in La Flandre, 3 (1869-1870), blz. 304 en 349.

$\left({ }^{23}\right)$ BRugGe, Rijksarchief, C. E. 2847.

(24) N. Huyghebaert, Le nécrologe de l'ancienne abbaye de SaintAndré-lez-Bruges, in Tablettes des Flandres 5 (1953), blz. 275, n. 25.

${ }_{\left({ }^{25}\right)}$ Visitatio monasterii $S$. Andreae juxta Brugas ... per illustrissimum et Reverendissimum Domnum Humbertum Guielmum episcopum Brugensem ... die septima junii I684. BRUGGE, Rijksarchief, 3709; zie hierover N. Huyghebaert, "Het leven van de H. Benedictus" door Dom Facob Cobrysse, schilder-monnik der Sint-Andriesabdij-bij-Brugge, in Album English, Brugge 1552, blz. 207-209.

(26) Brussel, A. R. A. Conseil d'État, 1284. 
De geschiedenis van zijn klooster moet zijn voornaamste liefhebberij geweest zijn. Niet alleen heeft hij de oude kroniek van Goethals aandachtig gelezen, zoals blijkt uit de randnota's van zijn hand, maar hij heeft ook een naamloze voortzetting ervan uit de XVIIe eeuw van een gewisse ondergang gered. Deze Continuatio van de Chronica Sancti Andreae, thans te Dendermonde bewaard in de bibliotheek van de SS. Pietersen Paulusabdij aldaar (hs. 40), draagt nog volgende aantekening aan de bovenrand van fol. I : „Liber monasterii S. Andreae juxta Brugas Flandrorum, inter rejectas schedulas inventus a me Balduino Boens, rel(igioso) p(res)b(yte)ro, $a^{0} \mathbf{1 7 0 9}$, die 16 Aprilis".

Boudewijn Boens zag er geen groot kwaad in, een handschrift van enige aantekeningen te voorzien. Zo heeft hij op nog ten minste twee andere handschriften van de kloosterbibliotheek nota's aangebracht : op de kroniek van Goethals, zoals we reeds deden opmerken (Brugge, Stadsbibliotheek ${ }^{669)}$ en op het Breve Compendium, thans bij de Bollandisten te Brussel (hs. 6ro). Zo vinden we in laatstgenoemd boekje, naast talrijke taalkundige verbeteringen, fol. $4 \mathrm{r}^{\mathrm{o}}$, de volgende aanvulling betreffende de eerste proosten van St-Andries : „Ceterum de Prepositis quales quotve fuerint ignoratum habemus; solummodo constat quod monasterium annis plus minus $87 \mathrm{sub}$ ipsis gubernatum in regulae observantia maxime floruerit et in temporalibus accreverit. Sub quibus etiam Balduinus Appula filius Roberti nostri fundatoris dedit nobis terram de Bensebroeck."

Andere aantekeningen betreffen de figuur van de bisschopabt Boudewijn Vilain (1509-1519). In de ogen van dom Boens was deze bisschop en benediktijn geworden Franciskaan een nog niet voldoende gewaardeerd heilige man. Zeker, Goethals beschrijft hem als , in multis valde laudabilis, sobrius, castus et devotus", maar hij voegt er aan toe : "Fuit etiam et sibi et aliis plus justo plerumque scandaloso parcus ,.. Daarmede kan Boudewijn Boens niet instemmen; in de rand merkt hij aan : " Haec a juvene non maturo sat judicio sunt scripta, unde caute legenda,${ }^{27}$

(27) BrugGe, Stadsbibliotheek, hs 569 fol. $121 \mathrm{r}^{0}$. 
Inderdaad was Arnout Goethals slechts 25 jaar, toen hij deze woorden neerpende, maar hij heeft toch Boudewijn Vilain nog gekend, en de herinneringen aan deze vrome doch al te spaarzame man waren nog levend toen hij zijn kroniek opstelde. ${ }^{29}$

Boudewijn Boens daarentegen dacht zijn oordeel op andere feiten te mogen steunen. Rond 1619 had men in de verlaten kloosterkerk van St-Andries het graf blootgelegd van Boudewijn Vilain en het lichaam, nog met de bisschoppelijke gewaden bekleed, werd ongeschonden teruggevonden. De abt, de in zeker opzicht ietwat angstvallige Henricus van den Zype, had het lichaam met ongebluste kalk laten bedekken, maar toen in December r669 zijn opvolger dom Benedictus van den Berghe (1659-1679) het stoffelijk overschot van zijn voorgangers liet overbrengen naar een grafkelder, die hij onder het O. L. Vrouwaltaar had doen in gereedheid brengen, vond men het lichaam van dom Boudewijn Vilain nog steeds gaaf en slechts oppervlakkig door de kalk aangevreten (corrosum, non corruptum). Geheel de communiteit was getuige van het wonder en dom Boens heeft hiervan tot tweemaal toe het relaas opgetekend: eens in de codex van de Bollandisten, waarin het zich nochtans reeds bevond, maar naar zijn oordeel niet in de juiste bewoordingen, ${ }^{29}$ en een tweede maal in de rand van de kroniek van Goethals. ${ }^{30}$

Dom Boens moet een groot belang aan dergelijke verschijnselen hebben gehecht; dat een lichaam enige tijd ongeschonden bewaard bleef, kwam hem steeds als een mirakel voor. Het geval deed zich eveneens voor na de dood van abt van den Zype, waarvan hij nochtans de „onbescheiden ijver" zo onomwonden had gebrandmerkt : ,... etsi corpus ejus etiam translatum tunc fuisset, sed etiamnum integrum repertum fuit

(28) Tussen 1524 en 1533. Arnout Goethals is in ${ }_{5} 518$ te St Andries binnengetreden; zie N. HuYGHEBAERT, Le chroniqueur Goethals, blz. 177.

$\left({ }^{29}\right)$ Uitg. W. H. James WAELE, Chronica monasterii Sancti Andreae, blz. I73; over het inrichten van een grafkelder te St Andries door abt van den Berghe, zie Chronica monasterii S. Andreae, blz. I53; vgl. N. Huyghebaert, Le culte marial à Saint-André, in Les Cahiers de Saint-André, II (1954), blz. I86-187.

$\left({ }^{30}\right)$ hs. 569 fol. $122 \mathrm{r}^{0}$. 
sarcophago corrupto: unde ibidem hactenus requiescit $\mathrm{a}^{0}$ I710. Ita est me vidente $a^{0}$ I669 et tangente. B. Boens pbr rel."31

Deze aantekening is meteen de laatste vermelding die we over Boens bezitten en verdiende daarom overgeschreven te worden. Toch moet hij nog enkele tijd geleefd hebben, daar hij de supprior Pieter Carlier, die in I710 nog in functie was, heeft opgevolgd. Het ligt voor de hand te veronderstellen dat de hoger beschreven catalogus van de bibliotheek, die wellicht kort na 1720 werd afgesloten, aan de vlijtige bibliothecaris is toe te schrijven. Het stuk zou hierdoor slechts aan waarde winnen. Doch het geschrift van het register verschilt te zeer van dat der randnota's die, zoals we gezien hebben, dom Boens eigenhandig in de aan zijn zorg toevertrouwde codices aanbracht $t^{32}$.

N. HuygheBaERT.

(31) Uitgegeven door W. H. James WeALE, Chronica monasterii Sancti Andreae, blz. I9r.

(32) Ons artikel over de Bibliotheek van de oude St-Andriesabdij was reeds ter perse, toen wij konden vaststellen dat het geschrift van de onbekende schrijver van de catalogus hetzelfde was als dat van een kroniekje in het Rijksarchief te Brugge bewaard: Breve compendium annalium tam spiritualium quam temporalium factum sub amplissimis dominis prelatis necnon fundatoribus hujus monasterii... Sti Andreae apostoli juxta Brugas (Découvertes II4). Jammer genoeg blijft ons de auteur van deze voor I7 Io opgestelde kroniek tot nu toe onbekend. 